\title{
Simulation of Accident-free Operation of the Modified Cultivator
}

\author{
Sergei Pirogov ${ }^{1,2}$, Sergei Kokoshin, and Dmitry Cherencov ${ }^{2}$ \\ ${ }^{1}$ Northern Trans-Ural State Agricultural University, Tyumen, Russia \\ ${ }^{2}$ Industrial University of Tyumen, Tyumen, Russia
}

\section{Abstract}

In the process of pre-sowing tillage, cultivating shovels on various stands are widely used. The type of stand affects the energy and quality indicators of the process. However these stands have one significant drawback: with the increase in the strength of soil resistance, there may be buckling of the stand, which leads to a decrease in the quality indicators of the process. To stabilize the depth of cultivating the soil with cultivating shovels on elastic stands, while maintaining the vibration effect, is possible to achieve through the use of cultivating stands with variable stiffness, made on the basis of a flexible tubular element. The work presents the results of calculating the stresses and strains of the design of the proposed cultivator stand under loading by

Corresponding Author:

Sergei Pirogov

piro-gow@yandex.ru

Received: 25 October 2019

Accepted: 15 November 2019

Published: 25 November 2019

Publishing services provided by

Knowledge E

(c) Sergei Pirogov et al. This

article is distributed under the

terms of the

Attribution License, which

permits unrestricted use and

redistribution provided that the

original author and source are

credited.

Selection and Peer-review under the responsibility of the AgroSMART 2019 Conference Committee. an external force. For research, the finite element method implemented in the ANSYS program was used. To simulate the movement of a cultivating shovel in the soil, we assumed the following - the treated soil was considered as a continuous medium. The tasks of constructing a grid model of the tubular element were solved, the horizontal component of the force exerted by the soil on the cultivator was determined, at which buckling occurs, the work of the cultivator shovel in the soil is modelled and the permissible speed is determined at which buckling of the flexible tubular element is eliminated.

Keywords: cultivator, stress, strain, buckling, flexible tubular element.

\section{Introduction}

Current trends in the development of the agricultural industry in Russia are aimed at resource and energy saving [1]. In livestock breeding, this trend is provided by indoor microclimate technologies [2, 3], in the field of logging -- monitoring of woody vegetation [4]. In the field of crop production, energy saving is aimed at reducing the traction forces of machinery during soil treatment $[5,6]$. The use of cultivator shovels during pre-sowing tillage is relevant not only for weed control but also for creating the optimal soil structure for seed growth and development, as well as the formation of an even seed bed [7]. In order to save energy for cultivating the soil, cultivators with elastic stands are used, 
a vibrational effect on the destructible soil layer $[8,9]$. However these stands have one significant drawback: with an increase in the strength of soil resistance, there may be buckling of the stand, which leads to a decrease in the quality indicators of the process.

To stabilize the depth of cultivating the soil with cultivating shovels on elastic stands, while maintaining the vibration effect, it is possible to achieve it through the use of cultivating stands with variable stiffness, made on the basis of a flexible tubular element [10].

The working body of the cultivator (Figure 1) consists of a cultivating shovel 1, mounted on a C-shaped stand 2. The stand is made of a flexible tubular element with a fitting 3 , which allows applying pressure to the cavity inside the element. The bracket 5 is used to mount the stand 2 to the frame 4.

The change in pressure in the inner cavity of the stand makes the free end with the cultivator shovel 1 to displace. In the process of cultivating the soil, the working body of the cultivator is affected by the resistance forces of the soil of a variable nature, which causes the stand to oscillate. The supply of working fluid through the nozzle 3 into the cavity of the stand 2 under variable pressure leads to oscillatory movements of the shovels with a certain amplitude and frequency.

The proposed design of the working body of the cultivator can reduce the traction resistance of tillage machines due to the effect of vibration when interacting with the soil, as well as improve the quality of the soil cultivation process by adjusting the rigidity of the stand [11, 12].

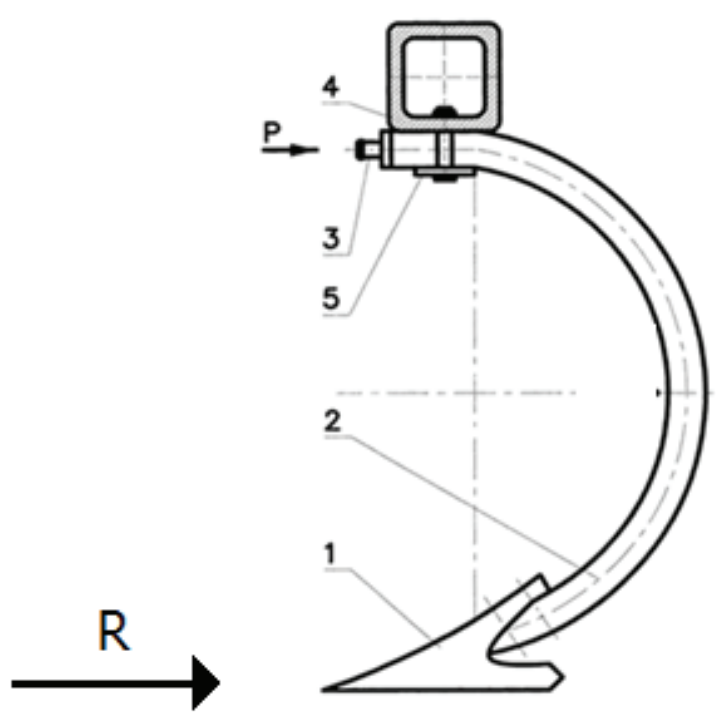

Figure 1: Cultivator working body. 
To calculate stresses and strains, the finite element method [13, 14], implemented in the ANSYS program, was used.

To ensure trouble-free operation of the cultivator, it is necessary to solve the following tasks:

1 Building a grid model of a tubular element;

2. Determining the horizontal component of the force of the soil on the coulter, at which buckling occurs;

3. Determining soil resistance forces on the cultivator shovel;

4. Determining maximum speed.

\section{Methods and Equipment}

\subsection{Methods}

The accuracy of the calculations will directly depend on the quality of the grid model of the structure under consideration. Rigid restraint (attachment point) and tip (working body) are built by default using the Sweep method, and to build a tube grid model, it is also necessary to determine the minimum size of elements that ensure the correctness of the solution without loss of accuracy.

To determine the optimal size of the grid element, we estimate how the displacement of the free end of the tube will change when a horizontal force of $1000 \mathrm{~N}$ affects the free end. Calculations in toolbox -- Static Structural are presented in Figure 2.

The displacement calculation results are presented in Figure 3.

Analysing the results obtained, we can conclude that with a decrease in the size of the elements of the grid model of the tube, the displacement of the free end tends to a certain limit, the minimum element size at which the deviation of the calculation results is less than $0.5 \%$ is $5 \mathrm{~mm}$.

To simulate the movement of a CS in the soil, we assume the following -- the treated soil will be considered as a continuous medium. The movement of an object in a continuous medium can be equivalently replaced by "flowing around" a body at rest with a continuous medium at the same speed; this approach will allow the use of ANSYS Fluent.

To determine the relationship between the horizontal component $\mathrm{R}$ and the velocity $\checkmark$ of the CS, we use the dependence:

$$
R=C_{x} F \frac{\rho V^{2}}{2}
$$


where $F$ is the mid-sectional area --- the largest cross-sectional area; $\rho$ is the density of the continuous medium (of the soil under consideration), $\mathrm{V}$ is the CS velocity in the soil, $C_{x}$ is a dimensionless coefficient characterized by the geometric component and the rate of flowing around with the continuous medium (i.e., it is a function of velocity).

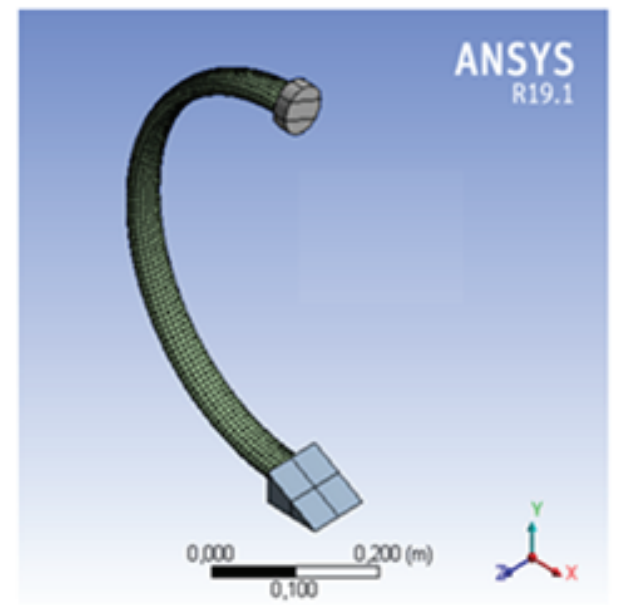

Figure 2: Cultivator stand model in SWEEP.

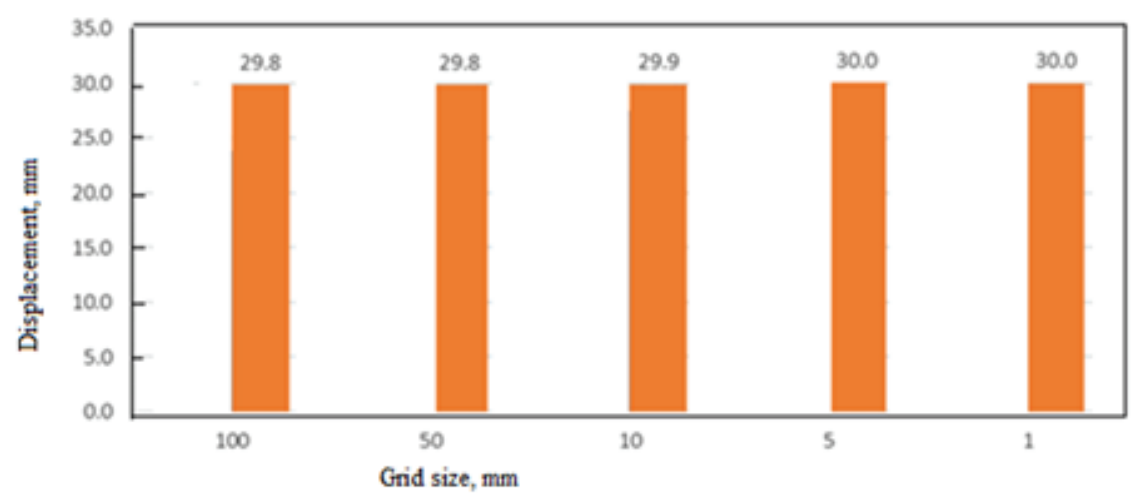

Figure 3: Calculation results of the displacements of the free end under the action of force.

So, $\mathrm{C}_{x}$ and the horizontal component $\mathrm{R}$ directly depend on the design of the CS. Let us evaluate the influence of the grid model and the size of its elements, as well as models of the behaviour of a continuous medium.

A schematic diagram of the cultivator shovel is shown in Figure 4.

\section{Results}

The hydrodynamic calculation was carried out in toolbox -- Fluent. The CS is made of steel, geometric characteristics: length -- 500 mm, height -- 200 mm, width -- 400 mm.

All hydrodynamic problems require an iterative approach to solving, we consider the change in the value of the drag coefficient $C_{x}$ depending on iterations and on the 


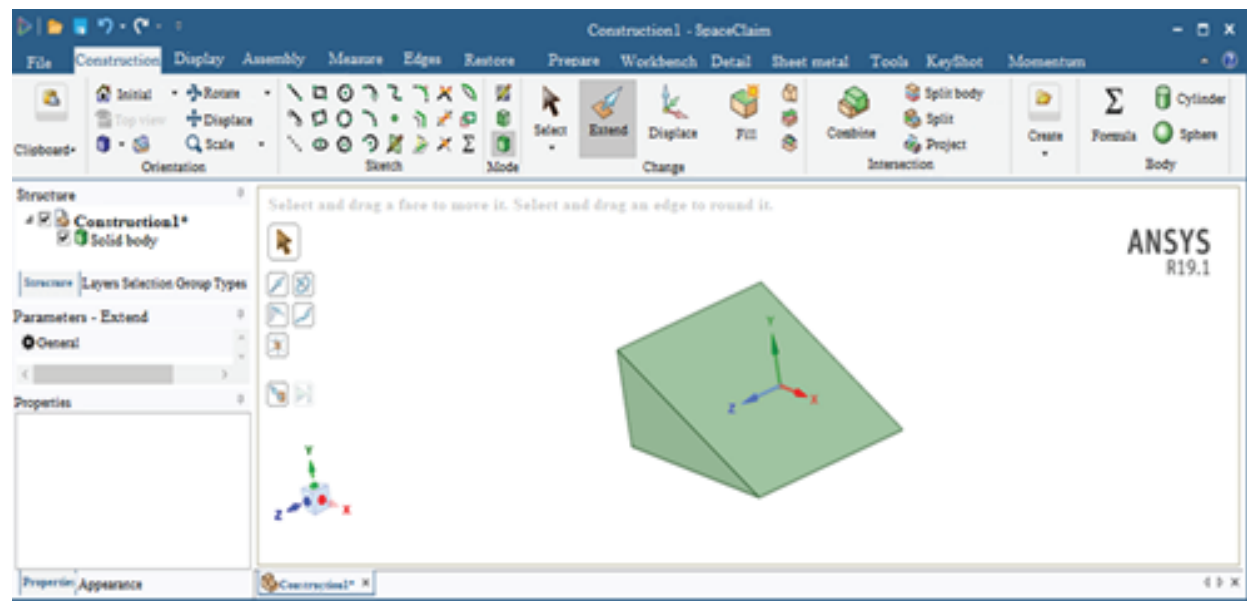

Figure 4: Schematic diagram of the cultivator shovel.

velocity of flowing around with a continuous medium for various models of continuous medium behaviour. The calculation results showed (Fig. 5), that to obtain reliable results, iterations may be limited to 300 .

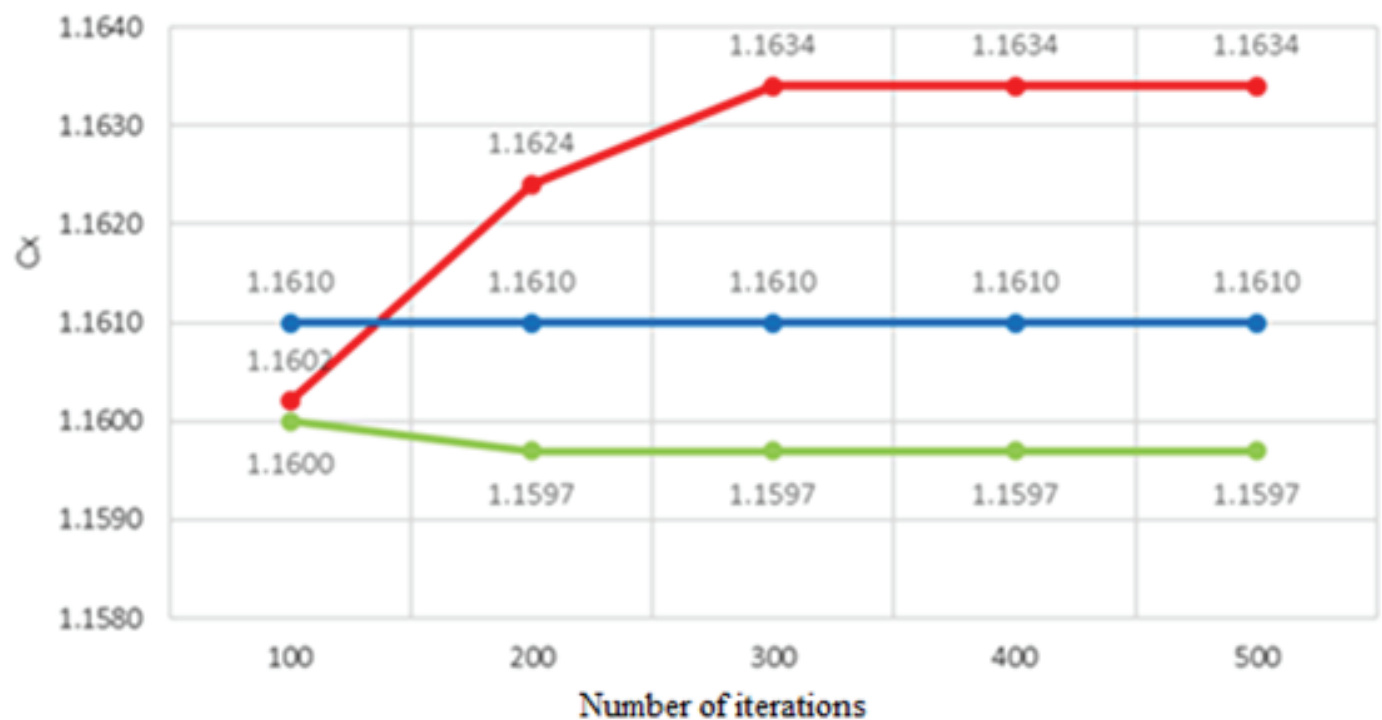

$\leadsto$ Laminarity model $\quad \longrightarrow$ Turbulence model k-w $\quad \longrightarrow$ Turbulence model k-e

Figure 5: Results of the evaluation of the influence of the number of iterations.

The distribution of velocities in the simulated volume is shown in Figure 6, and the effect of the movement velocity on the resistance force is shown in Figure 7. 


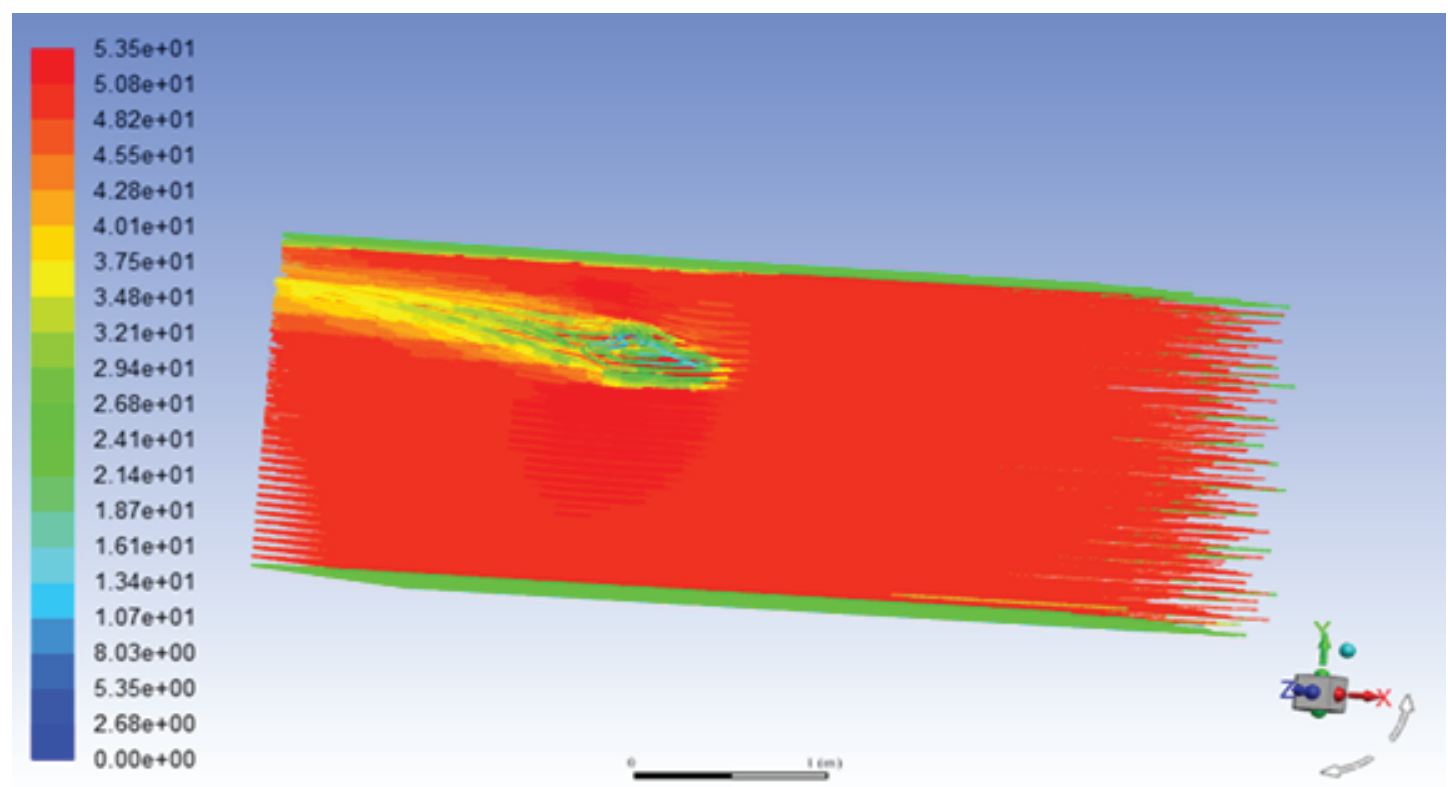

Figure 6: Velocity distribution in the simulated volume.

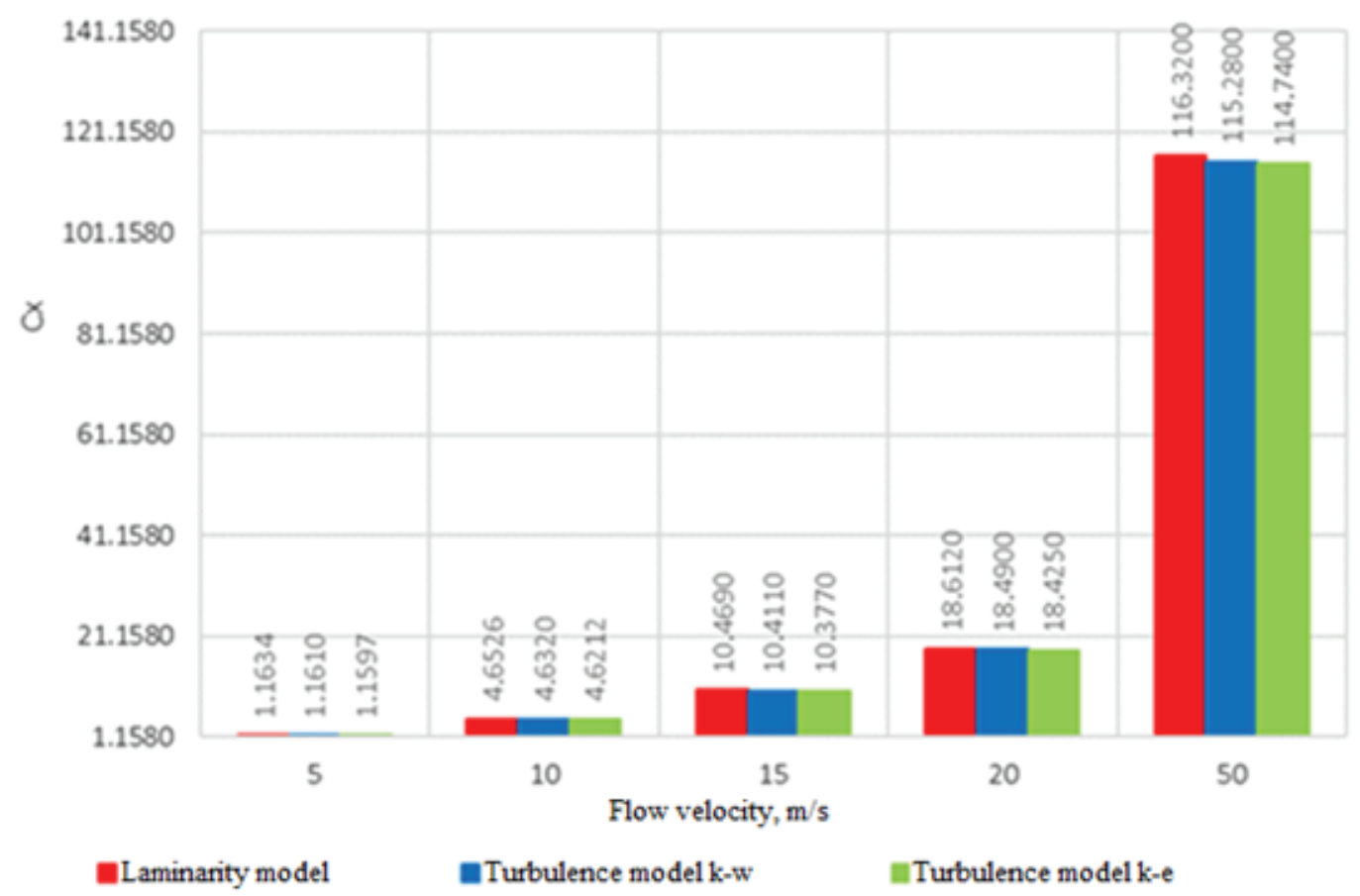

Figure 7: Results of the evaluation of the effect of flow velocity.

\section{Discussion}

During the mathematical calculations of the cultivator stand in the form of a flexible tubular element, it was revealed that the minimum size of the elements ensuring the correctness of the solution without loss of accuracy is $1 \mathrm{~mm}$. 
The analysis of the stress-strain state of the stand under the action of an external force of $1000 \mathrm{~N}$ showed that the movement of the shovel will be $30 \mathrm{~mm}$. For buckling of the proposed cultivator shovel, a horizontal force of at least $12800 \mathrm{~N}$ is required. This confirms a sufficient margin of safety for the stand. The maximum speed to eliminate buckling of the tubular element was about $25 \mathrm{~km} / \mathrm{h}$.

\section{Conclusion}

The mathematical analysis of the use of a flexible tubular element as a stand of a cultivator shovel showed that a soil resistance force of $1000 \mathrm{~N}$ causes the cultivator shovel to move up to $30 \mathrm{~mm}$. The proposed cross-section remains stable under the action of the resistance force of the soil up to $12800 \mathrm{~N}$, which in reality proves the possibility of using the proposed design even on heavy soils. The use of pulsating hydraulic pressure within the strength of the material will create a vibrational impact of the shovel on the soil and will help reduce traction resistance.

\section{References}

[1] Sandakov, T., Hasegawa, H., Sandakova, N. (2019). Optimum Design of a Chisel Plow for Grain Production in the Republic of Buryatia, Russian Federation. Ama-agricultural mechanization in asia africa and latin America, vol. 50, iss. 1, pp. 73--78.

[2] Andreev, L., Yurkin, V. (2017). Energy efficient technologies of microclimate creation in animal husbandry. Proceedings of the International Conference "Actual Issues of Mechanical Engineering" (AIME 2017). DOI: 10.2991/aime 17.2017.11.

[3] Andreev, L., Yurkin, V. (2018). Energy evaluation of production in agro-industrial complex. Proceedings of the International Conference "Actual Issues of Mechanical Engineering" (AIME 2018) series: Advances in Engineering Research, vol. 157, pp. 32--37

[4] Pobedinsky, V.V., Kruchinin, I.N., Pobedinsky, A.A. (2018). Intelligent system for determining the permittivity of the forest during radio frequency monitoring. Bulletin of the Samara Scientific Center of the Russian Academy of Sciences, vol. 20, no. 6(2), pp. 383--390.

[5] Belyaev V.I. (2018). Modern machinery and information technology in agriculture of the Altai Territory. Bulletin of Altai State Agricultural University, no. 8(166), pp. 158--162. 
[6] Blednyh, V.V., Svechnikov, P.G. (2014). Economic depth of basic tillage. Tractors and agricultural machines, no. 10, pp. 34--35.

[7] Kokoshin, S.N. (2018). Ensuring the depth of cultivation of soil cultivators by changing the rigidity of the rack. Bulletin of the Agroindustrial Complex of Stavropol, no. 1(29), pp. 14--17.

[8] Fedorov, S.E., Chatkin, M.N., Kostin, A.S., Urban, S.Yu. (2013). Modeling of the spring mounting of the combined cultivator. Tractors and agricultural machinery, no. 8. pp. $41-44$.

[9] Cherentsov, D.A., Pirogov, S.P., Kokoshin, S.N. (2018). Vibration Analysis of Cultivator Modification. Advances in Engineering Research, vol. 151, pp. 564--568.

[10] Kokoshin, S.N., Pirogov, S.P. (2018). Vibration Analysis of Cultivator Modification / Advances in Engineering Research. International Conference on Smart Solutions for Agriculture (Agro-SMART 2018), vol. 151, pp. 564--568

[11] Pirogov, S.P., Ustinov, N.N., Smolin, N.I. (2018). Mathematical Model of StressStrain State of Curved Tube of Non-Circular Cross-Section with Account of Technological Wall Thickness Variation. IOP Conference Series: Materials Science and Engineering,

[12] Chiorescu, E., Chiorescu, D. (2017). The variation of the unitary stresses occurring in the working part in relation to the type of soil, using the finite element method. Materials Science and Engineering, vol. 227, pp. 1--6.

[13] Bentaher, H., Ibrahmi, A., Hamza, E., Hbaieb, M., Kantchev, G., Maalej, A. (2013). Finite element simulation of moldboard--soil interaction. Soil and Tillage Research, vol. 134, pp. 11--16. 